\title{
APPLICATION OF STEEL FIBRES IN ALKALI-ACTIVATED MORTARS
}

\author{
Götz Hüsken ${ }^{a, *}$, Lars-Christian Wagner ${ }^{a, b}$, Gregor J. G. Gluth ${ }^{a}$, \\ Stephan Pirskawetz $^{a}$, HANs-CARsten KÜHNE ${ }^{a}$
}

${ }^{a}$ Federal Institute for Materials Research and Testing (BAM), Department of Safety of Structures (Dpt.7), Unter den Eichen 87, 12205 Berlin, Germany

${ }^{b}$ Technische Universität Berlin, Group of Building Materials and Construction Chemistry, Gustav-Meyer-Allee 25, 13355 Berlin, Germany

* corresponding author: goetz.huesken@bam.de

\begin{abstract}
Alkali-activated materials are ideal for the repair of concrete structures in harsh environmental conditions due to their high durability in chemically aggressive environments. However, slag-based mortars, in particular, are prone to shrinkage and associated cracks. In this respect, the application of steel fibres is one solution to reduce the formation of shrinkage induced cracks and to improve post cracking behaviour of these mortars. This study investigated the influence of two different types of steel fibres on the tensile properties of two alkali-activated mortars. Direct tensile tests and single fibre pull-outs were performed to analyse the determining failure modes both on macro and micro scale. Mechanical testing was accompanied by non-destructive testing methods such as digital image correlation and acoustic emission for a detailed analysis of the fracture process.
\end{abstract}

KEYWORDS: Alkali-activated materials, fibre pull-out, steel fibres, tensile strength.

\section{INTRODUCTION}

Alkali-activated materials (AAMs) have been an extensively investigated topic in material sciences as they are a suitable alternative to systems based on ordinary Portland cement (OPC), in certain applications. Much of the research covers design aspects using different precursor materials (such as fly ash or slag) and suitable alkaline activators (for example sodium silicates or sodium hydroxide) and how these variables influence mechanical and durability properties. These investigations show that AAM, depending on their varying composition, can meet or even surpass properties of OPC concretes [1] 3 .

Nevertheless, AAM often tend to be prone to higher shrinkage and more brittle behaviour than OPC concretes [4. Fibres, such as steel, glass, synthetic, and natural fibres, within the concrete matrix have often been used to increase ductility and to reduce the formation of shrinkage induced cracks. Adding fibres to the brittle matrix improves the post-cracking behaviour of the composite material significantly as the fibres connect the crack edges after cracks are formed. The application of fibres is usually limited to plastic fibres to reduce effects resulting from the formation of shrinkage cracks, but steel fibres are also of special interest for the application in AAM [5]. Besides reducing the formation of shrinkage induced cracks, the bond behaviour between steel fibres and the surrounding AAM matrix is in some cases stronger than in OPC concretes [6. However, this effect is not yet fully understood.

The application of steel fibres up to $2 \%$ to $3 \%$ by volume significantly increases both flexural behaviour and fracture energy of the AAM composite, which is mainly caused by the high tensile strength and ductility of the fibres [7]. Single fibre pull-out tests are a suitable test method to characterize the bond strength between steel fibres and the surrounding matrix [8]. These tests are common for OPC steel fibre-reinforced concretes but are seldom used for characterizing the fracture behaviour of AAM.

Steel fibre-reinforced AAMs prove to be alternatives to steel fibre-reinforced OPC in fields like repair tasks, underground engineering or pre-cast elements [9, 10]. It is thus important to investigate the failure mechanisms of steel fibre-reinforced AAM regarding:

(i) The influence of the fibre properties such as length, diameter and form on the mechanical properties of AAMs.

(ii) The influence of the (chemical) composition of the AAMs on the bond between the matrix and the fibres' surfaces.

(iii)How different compositions may lead to different failure modes and post-cracking behaviour.

\section{MATERIALS AND EXPERIMENTAL SETuP}

Two types of AAM based on ground-granulated blastfurnace slag (GGBS) and fly ash have been investigated in combination with two different steel fibres. The mortars are referred to as C7a (slag) and FA5 (fly ash), respectively. The composition of the investigated mortars is given in Table 1 . Further details on 
the mortars can be found in [11, 12]. The properties of the applied steel fibres are summarized in Table 2

\begin{tabular}{lcc}
\hline Material & $\mathrm{C} 7 \mathrm{a}\left(\mathrm{kg} / \mathrm{m}^{3}\right)$ & $\mathrm{FA} 5\left(\mathrm{~kg} / \mathrm{m}^{3}\right)$ \\
\hline Slag/fly ash & 574.3 & 579.7 \\
Activator 1 & 50.8 & 234.0 \\
Activator 2 & 89.0 & 71.4 \\
Water & 176.1 & 13.3 \\
Sand 0.1-0.5 & 400.6 & 402.0 \\
Sand 0.5-1 & 328.1 & 239.4 \\
Sand 1-2 & 374.2 & 239.4 \\
Sand 2-4 & 220.3 & 452.1 \\
\hline
\end{tabular}

Activator 1 - Sodium silicate solution with a modulus of 2.1 ('Grade D')

Activator 2 - $\mathrm{NaOH}$ solution.

TABle 1. Mortar composition.

\begin{tabular}{lcc}
\hline Property & Fibre 1 & Fibre 2 \\
\hline Length $(\mathrm{mm})$ & 13 & 20 \\
Diameter $(\mathrm{mm})$ & 0.2 & 0.3 \\
L/D ratio & 65 & 66.7 \\
Surface $\left(\mathrm{mm}^{2}\right)$ & 8.17 & 18.85 \\
Tensile strength $(\mathrm{MPa})$ & $>2600$ & $>1200$ \\
Max. tensile force $(\mathrm{N})$ & 81.68 & 84.82 \\
Density $\left(\mathrm{kg} / \mathrm{m}^{3}\right)$ & 7850 & 7850 \\
Fibres per $\mathrm{kg}$ & 314000 & 90110 \\
Coating & brass & none \\
\hline
\end{tabular}

TABle 2. Properties of steel fibres used.

Mixes with a steel fibre content (fibre type 1 ) of $1 \%, 2 \%$ and $3 \%$ by volume were tested for the mortar $\mathrm{C} 7 \mathrm{a}$ and $2 \%$ by volume for mortar FA5. The steel fibres of type 2 were added to mortar $\mathrm{C} 7 \mathrm{a}$ in such a quantity that their number per volume is comparable to the mix with $1 \%$ by volume ( $\left.\mathrm{C} 7 \mathrm{a} \_1 \% \_\mathrm{F} 1\right)$.

The direct tensile tests were performed according to the procedure described in 13 . The 56 days old specimens were tested in a displacement controlled uniaxial tension test with a loading rate of $0.0025 \mathrm{~mm} / \mathrm{s}$ until a total displacement of $1.5 \mathrm{~mm}$ was reached. To ensure uniform crack opening, both ends of the specimens were glued in the sample holders fixed to the servo-hydraulic testing machine (see Figure 1). Two linear variable differential transformers (LVDTs) were clamped laterally to the specimen to measure the deformation in the zone with constant cross section. The machine data (force and displacement) were recorded at a rate of $50 \mathrm{~Hz}$.

The tensile tests were accompanied by digital image correlation (DIC) and acoustic emission (AE) analysis. A high-contrast stochastic pattern was applied on the front side of the specimen for the DIC measurements. The optical deformation measurement was performed using an ARAMIS 5M system supplied by GOM, Gesellschaft für optische Messtechnik mbH.

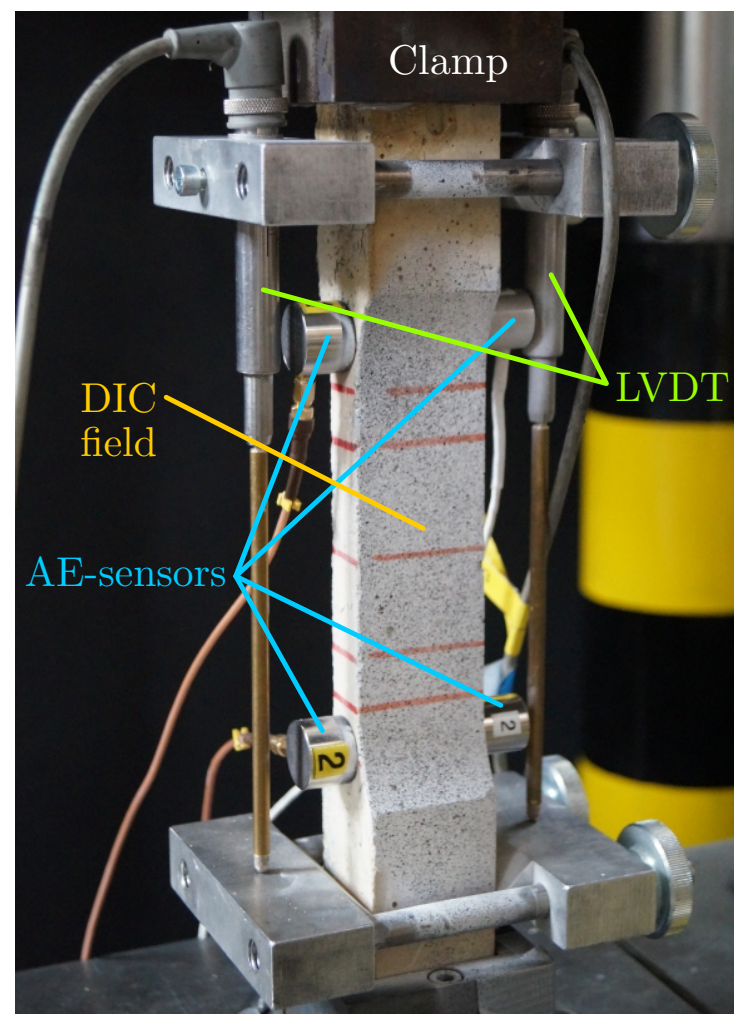

Figure 1. Test Setup.

The DIC system was either triggered by the testing machine and a signal was sent every $0.01 \mathrm{~mm}$ of piston displacement to the DIC camera or a fast measurement with 20 frames per second was conducted. 4 acoustic emission sensors (2 VS150MS and 2 PAC WD) were fixed to the specimen and acoustically coupled using viscoelastic adhesive pads BosticPrestik ${ }^{\circledR}$. The acoustic emission signals were processed and stored by an AMSY6 acoustic emission system supplied by Vallen Systeme GmbH. The detection threshold was set to $37.1 \mathrm{~dB}_{\mathrm{AE}}$ and the bandpass filter was set to $25 \mathrm{kHz}$ to $800 \mathrm{kHz}$ for all sensors.

Single fibre pull-out tests were conducted for all fibre-matrix combinations to characterize acoustic emission signals in terms of formation of micro cracks and fibre pull-out. The pull-out tests were performed displacement controlled with a loading rate of $0.0025 \mathrm{~mm} / \mathrm{s}$ until a pull-out length of $0.5 \mathrm{~mm}$ was reached and was then increased to $0.0333 \mathrm{~mm} / \mathrm{s}$ until total pull-out of the fibre. A detailed description of the sample preparation and further test details can be found in [14.

\section{Results And Discussion}

Figure 2 shows the averaged stress-strain plots (3 specimens for each mix) for the tested steel fibre combinations. The loading response of the tested mortars can be divided into three characteristic segments. Firstly, all samples show a linear-elastic behaviour until the maximum tensile stress (crack stress) is reached. This maximum tensile stress varies between $2.8 \mathrm{MPa}$ to 


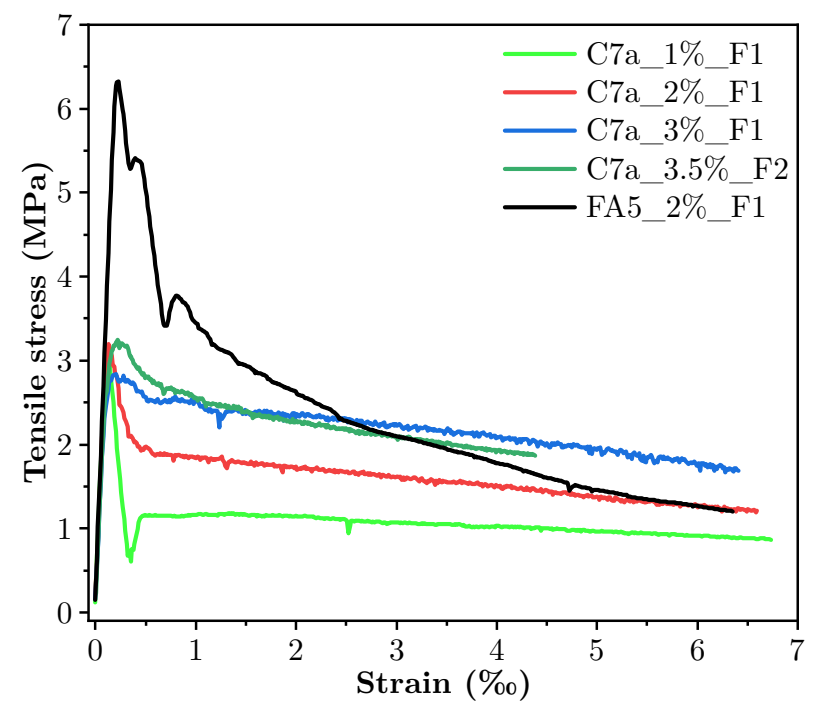

Figure 2. Averaged stress-strain curves.

3.2 $\mathrm{MPa}$ for the mortar C7a. FA5 has a stronger matrix and shows with $6.3 \mathrm{MPa}$ a maximum value that is about twice that observed for the tensile strength of C7a. Further loading beyond peak results either in a major drop of the tensile stress that stabilizes at a constant low level for low fibre contents or the gradual decrease of the tensile stress for higher fibre contents. The performance of the tested mortars under uniaxial tensile loading can be described according to [15] as strain-softening behaviour (Level 1).

Furthermore, the low deviation of the crack stresses of mortar C7a for all tested fibre contents demonstrates that incorporation of fibres does not increase the tensile strength of the material, but influences the post-critical behaviour beyond matrix cracking due to crack bridging [15]. Here, not only the fibre content is an important factor, but also the bond behaviour between the fibre and the surrounding matrix is essential. This fact is expressed by the area under the stress-strain plots beyond peak for mortars with same fibre content ( $2 \%$ by volume) but different matrix material ( $\mathrm{C} 7 \mathrm{a}$ and $\mathrm{FA} 5)$. In this case, the material with higher tensile strength (FA5) seems to have also the better bond between fibre and matrix.

Further insights into the post-critical behaviour of this composite material can be derived from the results of AE analysis and DIC measurements. Figure 3 shows as example the results of the AE analysis of specimen FA5_2\%_F1_3. In this diagram, the localized acoustic events and the applied tensile force are plotted versus time. Furthermore, a picture of the DIC measurement is added showing the strain distribution of the cracked specimen at the end of the tensile test. The localized acoustic events have been separated into two groups considering the weighted peak frequency (WPF) as suggested by [16]. The threshold of the WPF was set to $110 \mathrm{kHz}$. This value is based on preliminary tests where a clustering of acoustic events at $70 \mathrm{kHz}$ and $150 \mathrm{kHz}$ were observed.

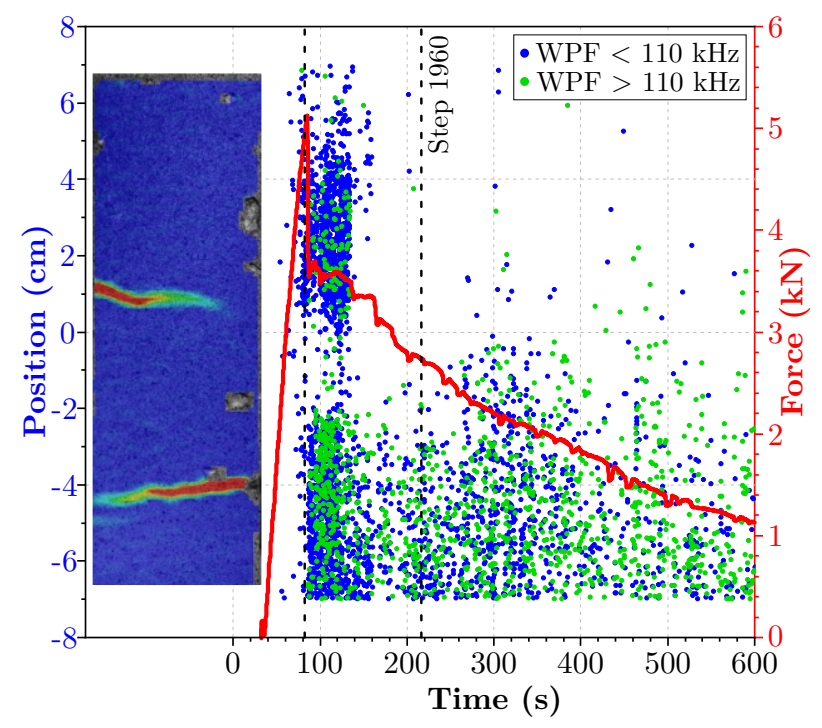

FiguRE 3. Results of the AE analysis for specimen FA5_2\%_F1_3.

Only few acoustic events have been detected in the uncracked state before maximum tensile stress. This low AE activity is related to the formation of micro cracks and increases rapidly in the upper part of the specimen shortly before crack formation causes a sudden drop in force. After the first crack is formed, the upper part of the specimen shows a high $\mathrm{AE}$ activity ( WPF $\leq 110 \mathrm{kHz}$ ) that indicates the activation of steel fibres due to the formation of micro cracks. Starting at 85 seconds, the AE activity increases in the lower part of the specimen, indicating the formation of a second crack. The AE activity near the upper first crack decreases significantly after the second crack is formed. AE events ( $\mathrm{WPF} \leq 110 \mathrm{kHz}$ ), indicating the formation of micro cracks, were mainly detected in the lower part of the specimen until the end, but their number decreases and higher frequency events (WPF $>110 \mathrm{kHz}$ ) dominate the fracture process in the lower part. These higher frequency events indicate fibre pull-out near the second crack as it occurs during crack opening.

The observations made by AE analysis regarding crack formation and crack opening are in good agreement with the results of the DIC measurements. Figure 4 shows the strain distribution of specimen FA5_2\%_F1_3 for relevant loading levels (steps). Additionally, the corresponding tensile stress ( $\mathrm{MPa}$ ) for each step is given in parenthesis in Figure 4 The corresponding steps of the DIC measurement are marked in Figure 3 by two dashed black lines. The first dashed line near the peak covers the time interval for the formation of the first and second crack, which is represented in Figure 4 by the steps 1070, 1071, 1087 and 1088. The second dashed line shows the time interval at step 1960 when mainly crack opening occurs.

Step 1070 shows the specimen shortly before the peak is reached. All other pictures taken before are similar and do not show any relevant strains. 


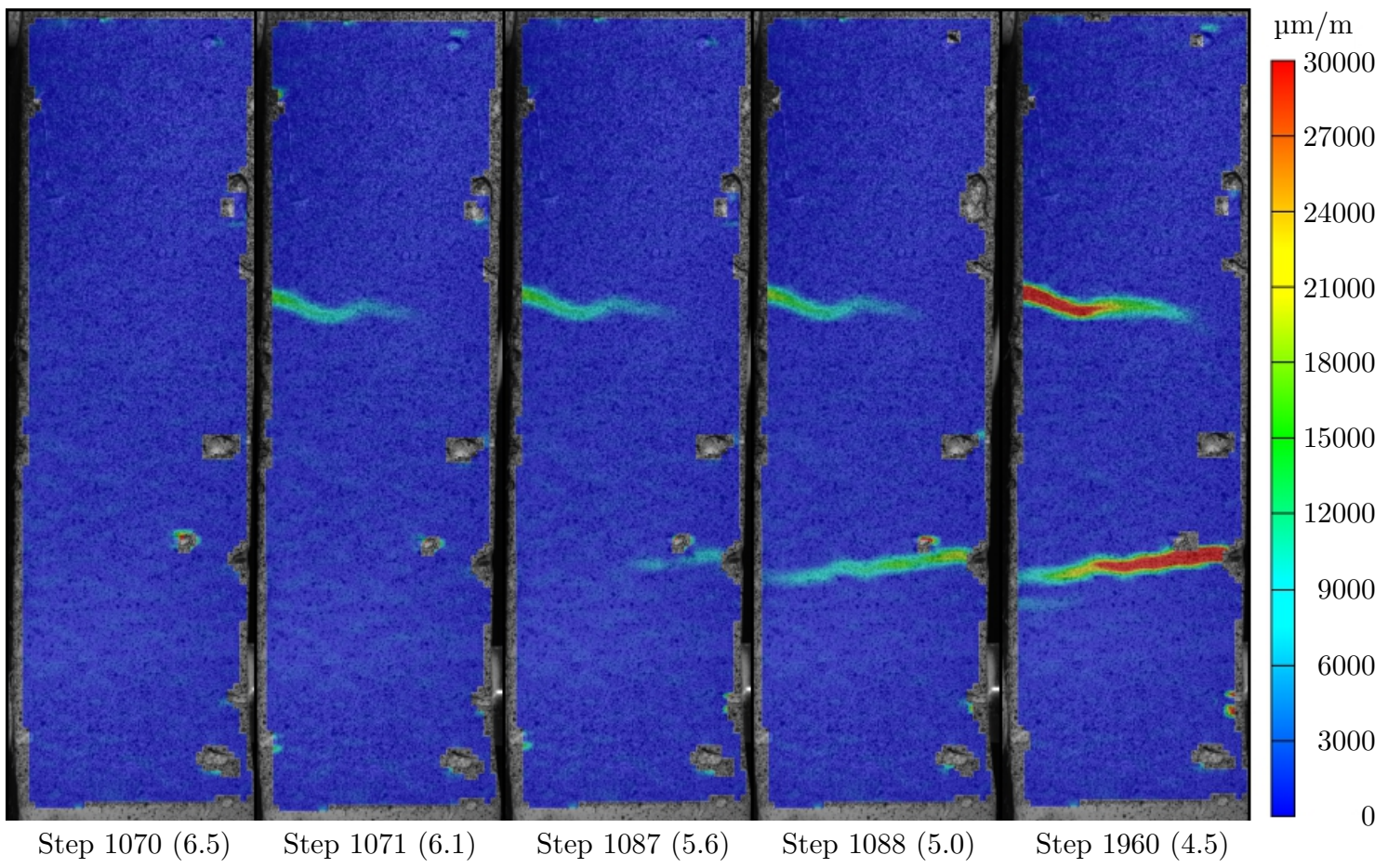

Figure 4. Strain distribution of sample FA5_2\%_F1_3.

Step 1071 was taken 0.05 s later and shows the formation of the first crack indicated by the strain concentration in the upper part of the specimen. The crack is formed from the left side of the specimen to the middle and results in a drop of the tensile stress of about $0.5 \mathrm{MPa}$.

Step 1087 was taken $0.8 \mathrm{~s}$ later and shows just a minor increase of the strains in the upper part. However, a second crack was formed in the lower part of the specimen, growing from the right side to the middle.

Step 1088 was taken, again, 0.05 s later and shows the rapid opening of the second crack, whereas the upper crack shows no significant changes in its strain distribution. The formation of the second crack results in a further drop of the tensile stress of about 0.6 MPa.

Step 1960 shows the strain distribution of the specimen at higher loading level when the tensile stress decreased to $4.5 \mathrm{MPa}$. The strain distribution in the upper part increases slightly, indicating an opening of the upper crack, but no lateral expansion to the right. The crack opening of the second crack is more dominant as it becomes evident from the larger increase in the strain distribution. Moreover, the lower crack runs through the entire front surface of the specimen.

Single fibre pull-out tests were conducted to get further insights into the fracture behaviour in the post-critical phase. Figure 5 shows typical loaddisplacement plots for both steel fibre types embedded in mortar $\mathrm{C} 7 \mathrm{a}$. In the beginning, the pull-out force increases linearly up to the maximum pull-out force. After reaching the peak, the force drops rapidly until a stable plateau is reached, which is dominated by the friction between the steel fibre and the surrounding matrix. In this phase, the pull-out force usually

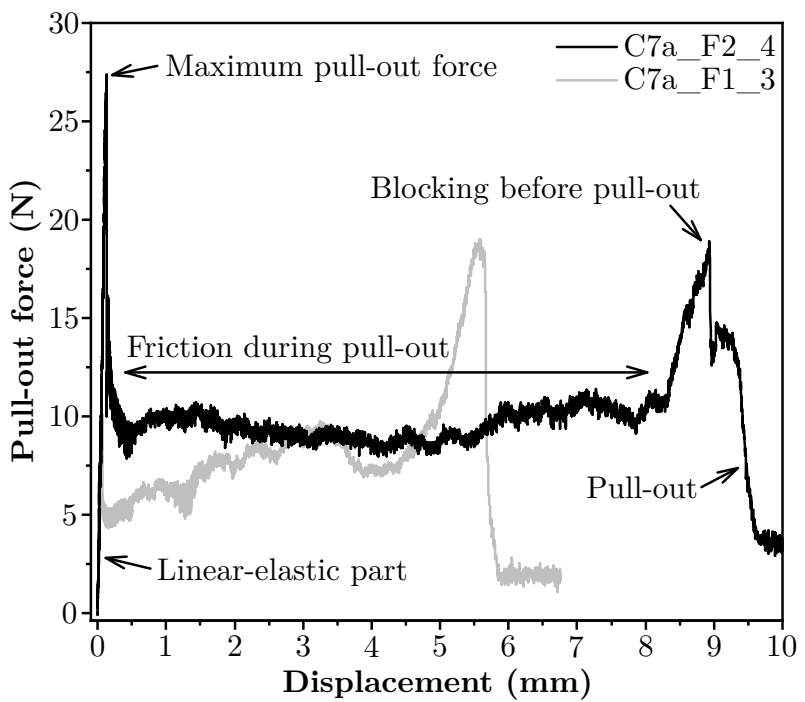

Figure 5. Load-displacement plots of steel fibres type 1 and 2 embedded in mortar $\mathrm{C} 7 \mathrm{a}$.

reaches a stable value or decreases slightly as with increasing fibre pull-out the force transmitting contact area between steel fibre and surrounding matrix decreases [17.

The pull-out force increases short before the fibre is pulled-out. Similar findings are reported by 15 and have been explained by the plastic deformation of the fibre end due to the cutting process. The deformation of the fibre ends provides a mechanical anchorage, which also may help increasing the pull-out resistance. Furthermore, it is possible according to 15 that some matrix particles adhere to the fibre surface. The abrasion of these particles and their accumulation 
towards the fibre pull-out end might cause a wedge effect leading to higher pressure on the fibre and higher frictional bond. Both effects could be confirmed for both steel fibre types by own SEM images as depicted in Figure 6 for the plastic deformation of the fibre end and Figure 7 for adhering matrix particles.

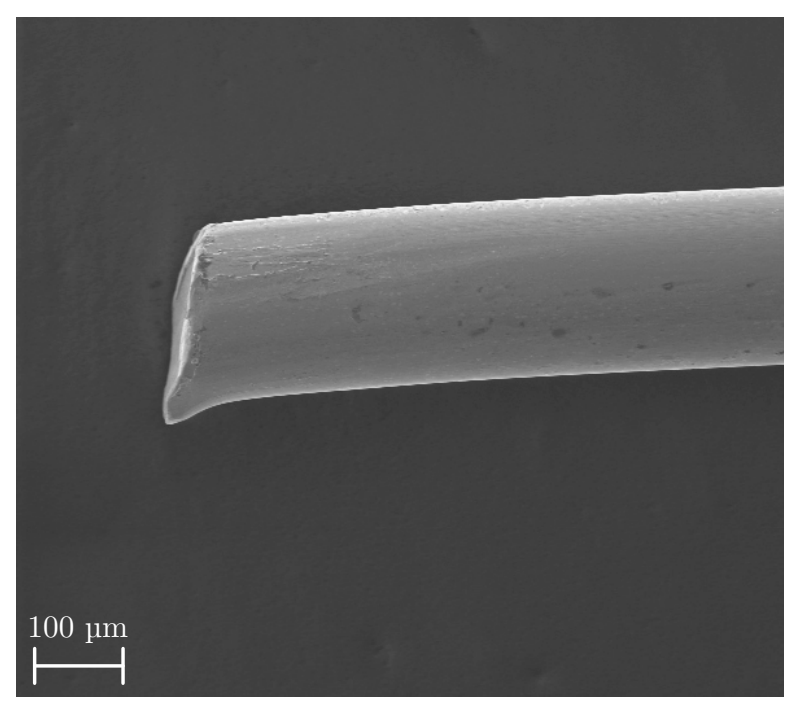

Figure 6. Plastic deformation of the fibre end due to the cutting process (steel fibre type 1).

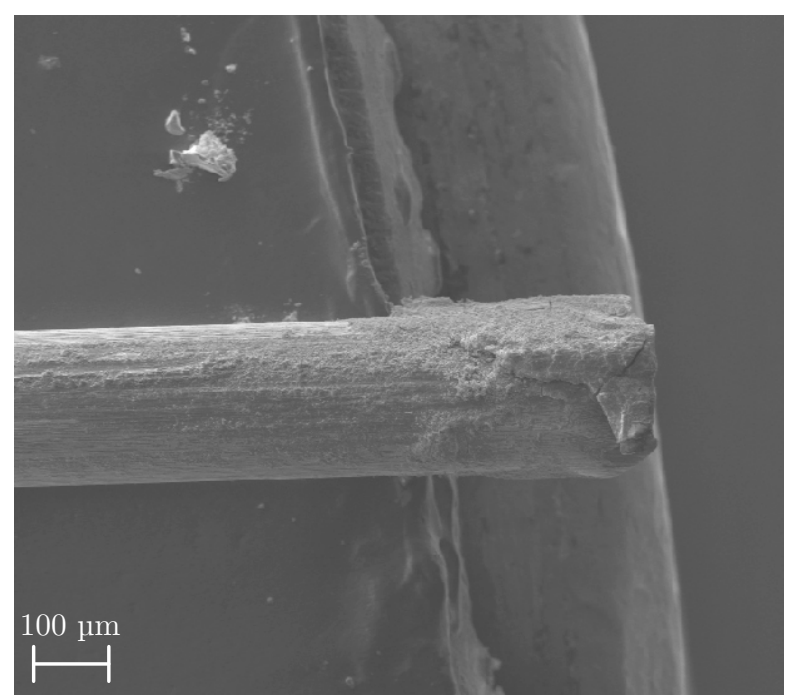

Figure 7. Adhering matrix particles $(\mathrm{C} 7 \mathrm{a})$ at the fibre end (steel fibre type 1).

It was already assumed from the averaged stressstrain plots that the bond behaviour between fibre and surrounding matrix of mortar FA5 is better than for mortar C7a. This assumption was confirmed by the results of the single fibre pull-out tests depicted in Figure 8 for steel fibres type 1. Here, not only a higher maximum pull-out force was obtained, but also the friction dominated pull-out phase differs from the results obtained for mortar C7a. In this case, the pull-out force decreases clearly with increasing fibre pull-out as the force transmitting contact area

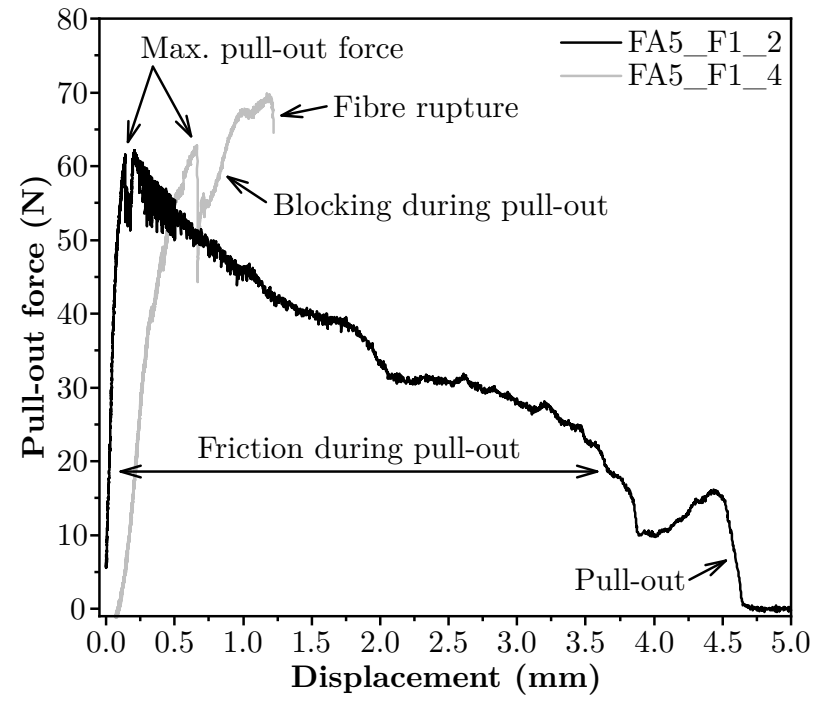

Figure 8. Load-displacement plots of steel fibres type 1 embedded in mortar FA5.

between steel fibre and surrounding matrix decreases. A slight increase in the pull-out force short before complete fibre pull-out was also recorded for steel fibres embedded in mortar FA5. However, fibre rupture occurred for both types of steel fibres at different levels (see Figure 9). Therefore, it was not possible to obtain comparable load-displacement plots for steel fibres type 2 as they all ruptured before the fibre was pulled-out from the matrix.

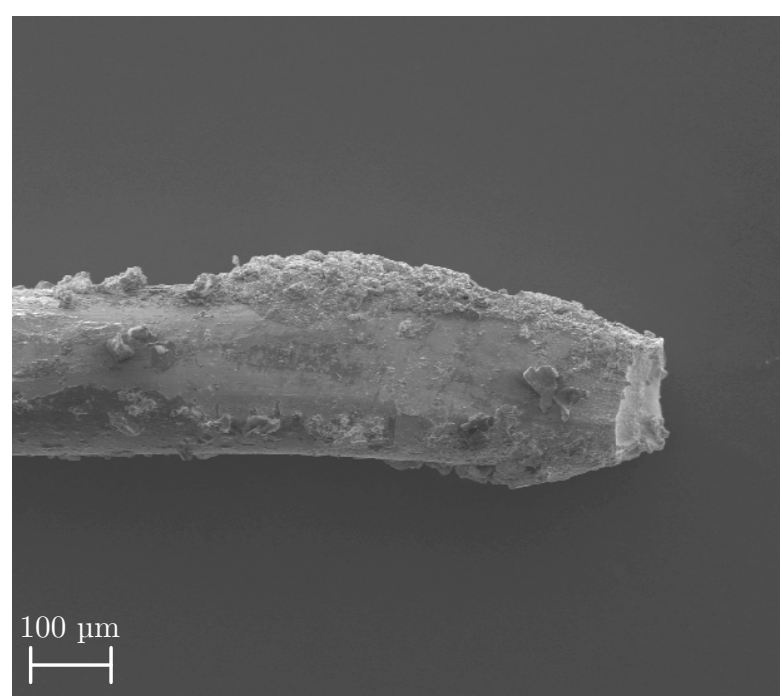

Figure 9. Ruptured fibre (steel fibre type 1) with adhering matrix particles (FA5).

\section{Conclusions}

Uniaxial tensile tests and single fibre pull-out tests have been conducted to characterize the determining failure modes of fibre-reinforced AAM. Two different AAM mortars have been investigated in combination with two types of steel fibres. The uniaxial tensile tests revealed that the post-critical behaviour is affected by the matrix properties (e.g. fibre-matrix bond), fibre 
content and type, whereas the cracking stress was only affected by the matrix strength. Single fibre pull-out tests confirmed the findings that the bond behaviour between embedded fibre and surrounding matrix is the main factor to control the post-critical behaviour of fibre-reinforced AAM.

The uniaxial tensile tests have been performed along with AE analysis and DIC measurements. Both techniques delivered valuable information on the determining failure modes in the post-critical phase. The results of the AE analysis demonstrated that it is possible to distinguish between the formation of micro cracks with low frequency and fibre pull-out with high frequency. Furthermore, increased AE activity near the formed cracks was measured which correlates well with the findings of the DIC measurements. The combination of both non-destructive test methods proved to be a useful tool for analysing failure mechanism of this composite material and optimizing material properties.

\section{ACKNOWLEDGEMENTS}

This study was undertaken as part of the BLEIB project within the Federal Institute for Materials Research and Testing (BAM) and funded by the Federal Ministry for Economic Affairs and Energy (BMWi), Germany. The authors gratefully thank Ms Berta Mota Gassó for her assistance with SEM imaging.

\section{REFERENCES}

[1] J. Provis, J. van Deventer (eds.). Alkali Activated Materials. Springer-Verlag GmbH, 2013.

[2] J. C. Petermann, A. Saeed, M. I. Hammons. Alkali-Activated Geopolymers: A Literature Review. Tech. rep., Air Force Research Laboratory - Materials and Manufacturing Directorate , 2010. DOI:10.21236/ada559113

[3] K. Arbi, M. Nedeljković, Y. Zuo, G. Ye. A Review on the Durability of Alkali-Activated Fly Ash/Slag Systems: Advances, Issues, and Perspectives. Industrial E Engineering Chemistry Research 55(19):5439-5453, 2016. DOI:10.1021/acs.iecr.6b00559.

[4] J. R. Yost, A. Radlińska, S. Ernst, et al. Structural behavior of alkali activated fly ash concrete. Part 2: structural testing and experimental findings. Materials and Structures 46(3):449-462, 2012. DOI:10.1617/s11527-012-9985-0.

[5] S. Bernal, R. M. de Gutiérrez, E. Rodríguez, et al. Mechanical behaviour of steel fibre-reinforced alkali activated slag concrete. Materiales de Construcción 59(293):53-62, 2009. DOI:10.3989/mc.2009.41807

[6] T. Ng, T. Htut, S. J. Foster. Mode I and II fracture behaviour of steel fibre reinforced high strength geopolymer concrete: an experimental investigation. In Proceedings of FraMCoS-7. 2010.

[7] S. S. Kumar, K. C. Pazhani, K. Ravisankar. Fracture Behaviour of Fibre Reinforced Geopolymer Concrete. Current Science 113(01):116-122, 2017. DOI:10.18520/cs/v113/i01/116-122
[8] K. Wille, A. E. Naaman. Bond stress-slip behavior of steel fibers embedded in ultra high performance concrete. In Proceedings of 18th European conference on fracture and damage of advanced fiber-reinforced cement-based materials, pp. 99-111. 2010.

[9] F. Pacheco-Torgal, J. B. de Aguiar, Y. Ding, et al. Performance of alkali-activated mortars for the repair and strengthening of OPC concrete. In Handbook of Alkali-Activated Cements, Mortars and Concretes, pp. 627-641. Elsevier, 2015. DOI:10.1533/9781782422884.4.627.

[10] A. Buchwald. What are geopolymers? Current state of research and technology, the opportunities they offer, and their significance for the precast industry. BFT International 72(7):42-49, 2006.

[11] N. Hu, G. Hüsken, G. J. G. Gluth, H.-C. Kühne. The Influence of Activator Composition on the Strength, Shrinkage and Chloride Migration Resistance of Alkali-Activated Slag Mortars. Key Engineering Materials 761:61-64, 2018. DOI:10.4028/www.scientific.net/kem.761.61.

[12] G. J. G. Gluth, W. D. A. Rickard, S. Werner, S. Pirskawetz. Acoustic emission and microstructural changes in fly ash geopolymer concretes exposed to simulated fire. Materials and Structures 49(12):52435254, 2016. DOI:10.1617/s11527-016-0857-x.

[13] S. M. Pirskawetz, G. Hüsken, I. Curosu, V. Mechtcherine. Combination of Digital Image Correlation and Acoustic Emission for Characterizing Failure Modes in Strain-Hardening Cement-Based Composites (SHCC). In Strain-Hardening Cement-Based Composites, pp. 300-307. Springer Netherlands, 2017. DOI:10.1007/978-94-024-1194-2_35

[14] L.-C. Wagner. Untersuchung des Einflusses von Stahlfasern auf das Bruchverhalten alkali-aktivierter Mörtel. Master's thesis, Technische Universität Berlin, Berlin, Germany, 2017.

[15] K. Wille, S. El-Tawil, A. Naaman. Properties of strain hardening ultra high performance fiber reinforced concrete (UHP-FRC) under direct tensile loading. Cement and Concrete Composites 48:53-66, 2014. DOI:10.1016/j.cemconcomp.2013.12.015

[16] M. Sause, T. Müller, A. Horoschenkoff, S. Horn. Quantification of failure mechanisms in mode-I loading of fiber reinforced plastics utilizing acoustic emission analysis. Composites Science and Technology 72(2):167174, 2012. DOI:10.1016/j.compscitech.2011.10.013.

[17] A. Khabaz. Analysis of sliding mechanism of straight steel fibers in concrete and determine the effect of friction. Archives of Civil and Mechanical Engineering 17(3):599-608, 2017. DOI:10.1016/j.acme.2017.01.005. 